\title{
Adsorption of raw and treated by membranes fermentation brines from table olives processing for phenolic compounds separation and recovery.
}

E. Ferrer-Polonio ${ }^{a,}{ }^{*}$, J.A. Mendoza-Roca ${ }^{\mathrm{a}}$, A. Iborra-Clar ${ }^{\mathrm{a}}$, L. Pastor-Alcañiz ${ }^{\mathrm{b}}$

a Instituto de Seguridad Industrial, Radiofísica y Medioambiental. Universitat Politècnica de València. Camino de Vera s/n, 46022, Valencia.

b DAM. Depuración de Aguas del Mediterráneo. Avda. Benjamin Franklin, 21. Parque Tecnológico. 46980 Paterna (Valencia).

* Corresponding author at: Instituto de Seguridad Industrial, Radiofísica y Medioambiental Universitat Politècnica de València Camino de Vera s/n 46022 Valencia. Tel. +34 963877630 Fax +34 963877639 .

e-mail address: evferpo@posgrado.upv.es, evaferrerpol@gmail.com

\begin{abstract}
BACKGROUND: Fermentation brines from table olive processing are effluents characterized by very high salinity and high organic matter concentration, which includes phenols of high value as hydroxytyrosol that is used by pharmaceutical and cosmetic industries.

RESULTS AND CONCLUSION: In this work the adsorption with a phenols-selective resin (MN200) of raw and pre-treated by ultrafiltration or by ultrafiltration plus nanofiltration
\end{abstract}


fermentation brine has been studied. The study included the adsorption and desorption process. Besides, the useful life of the resin was evaluated. Results indicated that resin MN200 above $20 \mathrm{~g} \cdot \mathrm{L}^{-1}$ yielded phenols separation efficiencies higher than $90 \%$. However, the adsorption of nanofiltrated effluent separated phenols more selectively. Adsorption kinetics fitted properly to a pseudo-second order kinetics and the Langmuir isotherm correctly model the adsorption process. Results of the intra-particle diffusion model show that the pore diffusion is not the only rate limiting step. Desorption was carried out with ethanol. More than $85 \%$ of phenolic compounds were recovered. The use of the resin during ten cycles showed that the nanofiltrated effluent increased the useful time of the resin.

Keywords: Fermentation brines; Phenols adsorption; Phenols recovery; Polymeric resin; Table olive processing.

\section{INTRODUCTION}

Olive oil and table olives are recognized as valuable sources of natural phenolic antioxidant compounds that provide health benefits. These natural antioxidants have applications against reactive species involved in aging and in inflammatory, coronary and degenerative diseases. ${ }^{1-}$

3 Therefore, the phenolic compounds from olives have applications as food additive, as pharmaceutical active substance and as a cosmetic ingredient.

Phenolic content of olive oil and oil mill wastewater have been thoroughly investigated. Thus, several studies about their phenolic compounds concentration can be found in the 
literature. ${ }^{4-7}$ Nevertheless, there are only a few studies focused on phenolic compounds of table olives effluents. ${ }^{8,9}$

Spain is the largest producer of table olives in the world, followed by Turkey, Egypt, Syria, Algeria, Argentina and Greece. The average world production was 2,472,700 tons, between 2009 and 2014, corresponding 524,700 to the Spain's production, i.e. $21 \%$ of the world production. $^{10}$

The aim of the table olive processing is to remove bitterness from the fruit caused by oleuropein (characteristic polyphenol of the olives). This process entails three steps. Firstly, olives are submerged for $8-12$ hours in sodium hydroxide solution $(1-2 \% \mathrm{w} / \mathrm{v})$, and oleuropein is hydrolysed. ${ }^{11}$ Secondly, the sodium hydroxide solution is removed, and two or three rinses cycles are performed to eliminating the excess alkali. In the final step, olives remain immersed in brine $(4-8 \% \mathrm{w} / \mathrm{v}$ of sodium chloride) for several months.

During Spanish-style green olive processing there is an osmotic exchange between fruit and brine. Consequently, important changes in composition occur; mainly on soluble sugars, $\mathrm{NaCl}$ and phenolic compounds. ${ }^{12}$ Thus, there is an important loss of phenolic compounds in olive fruit, due to the diffusion of these compounds to the brine. In this way, concentrations of protocatechuic acid, ferulic acid and oleuropein decrease in olives, meanwhile the phenols concentration increases in brines. The main phenolic compounds in wastewaters from the fermentation step of table olive processing (FTOP) are hydroxytyrosol (HTY) and tyrosol (TY). ${ }^{13,14}$ The concentration of hydroxytyrosol is due to acid and enzymatic hydrolysis of oleuropein. Tyrosol may arise from the hydrolysis of ligstroside, a heterosidic ester of tyrosol and elenolic acid. The evolution of other phenolic compounds (caffeic, gallic, phydroxyphenylacetic, vanillic and benzoic acids) depends on the olive maturation stage. ${ }^{15}$ Hydroxytyrosol has the highest antioxidant capacity of these phenolic compounds. Besides, 
hydroxytyrosol has better properties than other natural antioxidants such as vitamin C, vitamin E or resveratrol. ${ }^{16}$

FTOP wastewater corresponds with the $20 \%$ of the total wastewater volume generated in all stages of table olive processing, which is about $3.9-7.5 \mathrm{~m}^{3}$ per ton of green olives. ${ }^{17}$ However, FTOP contributes to the $80-85 \%$ of the total pollution. ${ }^{18}$ Therefore, it is of great interest to treat it separately. FTOP wastewater is an acidic stream (pH around 4) and its conductivity is very high, showing values close to $80 \mathrm{mS} \cdot \mathrm{cm}^{-1}$. Suspended solids (SS) concentration is also high (around $1000 \mathrm{mg} \cdot \mathrm{L}^{-1}$ ), what implies high turbidity values. The concentrations of organic matter and total phenols are highly variable, and they depend primarily of processing method, cultivar and maturation degree. ${ }^{9}$ Soluble COD can range between 6,000 and $15,000 \mathrm{mg} \cdot \mathrm{L}^{-1}$, and total phenols concentration ranges among 500 and $1,500 \mathrm{mg} \mathrm{TY} \cdot \mathrm{L}^{-1}$.

The above mentioned characteristics make FTOP wastewater treatment very difficult. The application of a biological process is complicated because salinity shocks cause physical and biochemical changes of the activated sludge and phenolic compounds can inhibit biomass, primarily by bactericidal effect. ${ }^{19}$ Other possible treatments are electro-coagulation, ${ }^{20}$ ozonation or Fenton's oxidation ${ }^{21}$ but they are expensive and inappropriate for large wastewaters volumes. In addition, these treatments imply phenols destruction and valuable phenolic compounds would not be recovered.

Some techniques allowing phenol recovery or concentration from water solutions are membrane technologies and adsorption. Membrane processes, in particular ultrafiltration, nanofiltration and reverse osmosis have been reported for many authors for concentrating phenolic compounds from olive mill wastewater, ${ }^{21,22}$ but they have not been reported for FTOP wastewater. Adsorption is one of the best techniques to eliminate phenolic compounds 
in liquid-phase. There are several papers reporting phenols adsorption efficiency of activated carbon, $^{23,24}$ new low-cost adsorbents ${ }^{25-27}$ or polymer adsorbents. ${ }^{28,29}$ The most usual adsorbents for phenols separation in water treatment are activated carbons, but phenols recovery is difficult. Irreversible adsorption in carbon may be given by adsorbate bonding to specific functional groups on the active sites of the adsorbent or by oxidative polymerization of phenolic compounds onto the surface..$^{25}$ Nevertheless, polymeric adsorbents have feasible regeneration under mild conditions and the most commonly used ones are based on polystyrene adsorbents crosslinked with divinylbenzene..$^{30,31}$

In the present work, adsorption of phenols in FTOP effluents has been studied with the nonionic polymeric resin. Samples of both raw FTOP wastewater and FTOP effluents after membrane filtration (ultrafiltration and nanofiltration) were subjected to adsorption. Adsorption and desorption (by organic solvents) of phenolic compounds were evaluated. Besides, it has to be mentioned that this study includes experiments for resin reuse in different adsorption/desorption/activation cycles.

\section{MATERIALS AND METHODS}

\subsection{Wastewater}

Fermentation brine was provided by a table olive packaging industry located in Comunidad Valenciana (Spain). Experiments and characterization were carried out with two fermentation brine samples, which were previously filtered in a $60 \mu \mathrm{m}$ sieve. Little pieces from olives that could be present in the FTOP and 35-40\% of SS were removed in this step. The filtered samples were named FTOP-1 and FTOP-2. 15 L of FTOP-1 and FTOP-2 were ultrafiltrated 
using a $5 \mathrm{kDa}$ polyethersulfone membrane (UP005) supplied by Microdyn-Nadir. Transmembrane pressure (TMP) in the ultrafiltration was 2.5 bar. Ultrafiltrated samples were named UF-1 and UF-2. Finally, 10 L of UF-1 was filtered at a TMP of 15 bar with a nanofiltration membrane (NF245) supplied by Dow. The main characteristics of this membrane are the negligible rejection of monovalent ions and the molecular weight cut-off of $300 \mathrm{Da}$. The NF permeate was named NF-1. Before their use, all wastewater samples were stored at a temperature of $4^{\circ} \mathrm{C}$.

\subsection{Adsorption Resin.}

Adsorption tests were performed using MN200 resin. This resin was selected from previous tests (data not shown). MN200 was nonionic polymeric resin provided by Purolite Lt. It has a macroporous structure of polystyrene crosslinked with divinylbenzene and its physical appearance is spherical beads. Resin was conditioned in sodium hydroxide solution $(2 \% \mathrm{w} / \mathrm{v})$ for $60 \mathrm{~min}$ (mixing at $150 \mathrm{rpm}$ ) and then in water for $5 \mathrm{~min}$ (twice, mixing at $150 \mathrm{rpm}$ ) before being used on the adsorption experiments. Characteristics of the MN200 are shown in table 1.

Table 1. Physical and chemical characteristics (data from supplier).

\begin{tabular}{lc}
\hline & MN200 Characteristics \\
\hline Functional group & None \\
Ionic form & None \\
Moisture retention & $57-61 \%$ \\
Mean diameter & $535 \pm 85 \mu \mathrm{m}$ \\
Uniformity coefficient (max.) & 1.4 \\
Pore volume & $1-1.1 \mathrm{~mL} \cdot \mathrm{g}^{-1}$ \\
Surface area (min.) & $900 \mathrm{~m}^{2} \cdot \mathrm{g}^{-1}$ \\
d50, Meso and Macropores & $800 \AA$ \\
d50, Micropores & $15 \AA$ \\
Specific gravity & 1.04 \\
Shipping Weight (approx.) & $655-685 \mathrm{~g} \cdot \mathrm{L}^{-1}$ \\
\hline
\end{tabular}


The MN200 has a hydrophobic matrix, and it has no properties for ion exchange, hence operating performance can be enhanced by the presence of electrolytes in the aqueous phase, increasing the differential hydrophilicity/organophilicity between the water and the adsorbent phase. As commented, the high $\mathrm{NaCl}$ concentration in FTOP wastewater can improve adsorption process.

\subsection{Analysis.}

$\mathrm{pH}$ and conductivity measurements were carried out with pH-Meter GLP 21+ and EC-Meter GLP 31+ (CRISON), respectively. COD was analysed using kits and a Spectrophotometer DR600 (HACH LANGE). Suspended solids (SS) were measured according to APHA, 2005. ${ }^{32}$ Colour was determined as the difference of absorbance at 440 and $700 \mathrm{~nm}$ according Castro and Brenes. ${ }^{33}$

Total phenols were measured spectrophotometrically according to the Folin-Ciocalteu method. ${ }^{34}$ Sodium carbonate $(20 \% \mathrm{w} / \mathrm{v})$ from PANREAC and Folin \& Ciocalteu's reagent from Sigma Aldrich were used for it. Results were expressed as equivalent ppm of tyrosol $\left(\mathrm{mg} \mathrm{TY} \cdot \mathrm{L}^{-1}\right)$.

For phenolic profile measurement by high-performance liquid chromatography (HPLC), all samples were previously treated in order to extract phenols according to El-Abbassi et al. ${ }^{35}$ Extracts were brought to dryness in a rotary evaporator (Rotavapor R-114 from BÜCHI) at $40^{\circ} \mathrm{C}$. The samples $(7 \mathrm{mg})$ were reconstituted in $1 \mathrm{~mL}$ of MetHQ, where MetHQ was hydroquinone at $0.5 \mathrm{mg} \cdot \mathrm{mL}^{-1}$ in methanol. Hydroquinone was used as internal standard. Analyses were carried out with a Jasco HPLC system equipped with a MD-2018 Photodiode Array detector. The separation was carried out using a Phenomenex Kinetex 5u Biphenyl 
100A column $(4.6$ x $250 \mathrm{~mm}, 5 \mu \mathrm{m})$. The optimal chromatographic conditions were established: flow rate of $1.5 \mathrm{~mL} \cdot \mathrm{min}^{-1}$; injection volume of $10 \mu \mathrm{L}$; solvent system were phase A ( $1 \%$ acetic acid in water) and phase B (1\% acetic acid in methanol); gradient conditions: the elution started at $5 \%$ of $\mathrm{B}$ and remained constant for $1 \mathrm{~min}$, it linearly increased up to $80 \%$ of $\mathrm{B}$ in $25 \mathrm{~min}$ and returned to $5 \%$ of $\mathrm{B}$ in $2 \mathrm{~min}$. This elution was held for $3 \mathrm{~min}$ before the next injection. External calibration curves were obtained for different analytes in different concentrations which were dissolved in the MetHQ solution and injected in triplicate.

\subsection{Adsorption.}

Adsorption of phenolic compounds was carried out with batch experiments (Flocumatic 4 jartest apparatus from JP SELECTA) at room temperature $\left(21 \pm 1^{\circ} \mathrm{C}\right)$. The MN200 concentrations in the jar-tests were 5, 10, 20, 30 and $40 \mathrm{~g} \cdot \mathrm{L}^{-1}$. Resin was mixed with $200 \mathrm{~mL}$ of the FTOP-1, FTOP-2, UF-1, UF-2 and NF-1. Experiments were performed for $180 \mathrm{~min}$ at a constant speed of $150 \mathrm{rpm}$.

The extent of adsorption was determined by measuring the residual amount of total phenols in the liquid phase, throughout the experiment. COD and colour were analyzed at the end of the experiments. The equilibrium adsorption time was calculated and adsorption kinetics of pseudo first-order reaction, pseudo second-order reaction and intra-particle diffusion model were analysed. Besides, data were represented in order to find out whether they followed the behavior of the Langmuir or Freundlich isotherms. Finally, the influence of resin dosage, initial characteristics of the samples and pre-treatment performed on phenol adsorption was evaluated. 
After adsorption, the MN200 resin was separated from the liquid phase. Then, it was washed twice with distilled water $(5 \mathrm{~min}$ at $150 \mathrm{rpm})$ and dried in an oven for 3 hours at $50^{\circ} \mathrm{C}$.

\subsection{Desorption.}

\subsubsection{Organic solvent selection for phenols recovery.}

Batch experiments at room temperature $\left(21 \pm 1^{\circ} \mathrm{C}\right)$ were performed using NF-1 aliquots. Ethanol and ethyl acetate were compared. Firstly, it was carried out the adsorption phase using $500 \mathrm{~mL}$ of NF-1 with $20 \mathrm{~g} \cdot \mathrm{L}^{-1}$ of $\mathrm{MN} 200$, according to the adsorption protocol (section 2.4). Desorption was performed with $4 \mathrm{~g}$ of the resin and $200 \mathrm{~mL}$ of solvent, for $60 \mathrm{~min}$ at a constant speed of $150 \mathrm{rpm}$. Then, it was determined the amount of total phenols in the liquid phase.

\subsubsection{Phenols recovery.}

For every resin used in the adsorption experiments explained in section 2.4 , desorption was carried out for phenols recovery. Experiments were performed at room temperature $(21 \pm$ $1^{\circ} \mathrm{C}$ ), for $60 \mathrm{~min}$ at a constant speed of $150 \mathrm{rpm}$. During the experiments, data of total phenols in the liquid phase were collected. The equilibrium desorption time was calculated. Besides, relationship with phenol adsorption and dosage resin, initial characteristics of the samples and pre-treatment performed, was studied. 


\subsection{Useful life of MN200.}

Operating cycles were carried out in view of estimating the lifetime of the MN200 resin. The aim of this experiment was to study the relationship between the three types of effluents (raw, ultrafiltered and nanofiltered FTOPs) and service life of the resin. Experiments were performed at room temperature $\left(21 \pm 1^{\circ} \mathrm{C}\right)$ with $30 \mathrm{~g} \cdot \mathrm{L}^{-1}$ of the $\mathrm{MN} 200$ and $200 \mathrm{~mL}$ of the FTOP-2, UF-2 and NF-1. Each cycle involved: initial conditioning or activation with $\mathrm{NaOH}$ $(2 \% \mathrm{w} / \mathrm{v})$, adsorption and desorption. Conditioning or activation was performed according to the above mentioned protocol (section 2.2). Adsorption and desorption were performed for the equilibrium time at a constant speed of $150 \mathrm{rpm}$. After adsorption and desorption, the MN200 was washed twice in water (5 min at $150 \mathrm{rpm}$ ) and dried in an oven for 3 hours at $50^{\circ} \mathrm{C}$.

\section{RESULTS AND DISCUSION.}

\subsection{Wastewater characterization.}

The characterization of the wastewaters used in the experiments is shown in table 2 . Parameters were measured in triplicate, and the standard deviation for each one also is presented in this table.

Table 2. Wastewaters characterization.

\begin{tabular}{ccccccc}
\hline Sample & $\mathbf{p H}^{(*)}$ & $\begin{array}{c}\text { Conductivity } \\
\left(\mathbf{m S . c m}^{(* *)}\right)\end{array}$ & $\begin{array}{c}\text { SS } \\
\left(\mathbf{m g}^{-\mathbf{1}}\right)\end{array}$ & $\begin{array}{c}\mathbf{C O D} \\
\left(\mathbf{m g}^{-\mathbf{L}^{-1}}\right)\end{array}$ & $\begin{array}{c}\text { Total phenols } \\
\left(\mathbf{m g ~ T Y} \cdot \mathbf{L}^{-1}\right)\end{array}$ & Colour \\
\hline FTOP-1 & 4.4 & 79.2 & $1105 \pm 56$ & $9730 \pm 65$ & $1013 \pm 8$ & $0.458 \pm 0.003$ \\
FTOP-2 & 4.2 & 79.8 & $1026 \pm 33$ & $8570 \pm 42$ & $791 \pm 12$ & $0.429 \pm 0.011$ \\
UF-1 & 4.3 & 78.0 & 0 & $7662 \pm 13$ & $956 \pm 9$ & $0.252 \pm 0.008$ \\
UF-2 & 4.2 & 80.5 & 0 & $7301 \pm 23$ & $722 \pm 16$ & $0.194 \pm 0.007$ \\
NF-1 & 4.2 & 69.9 & 0 & $4970 \pm 15$ & $710 \pm 16$ & $0.172 \pm 0.003$ \\
\hline
\end{tabular}

${ }^{(*)} \mathrm{pH}$ standard deviations were between 0.1 and 0.2

${ }^{(* *)}$ Conductivity standard deviations were between 0.3 and 1.2 
Results confirm that FTOP is a very saline effluent (conductivities between 70 and 80 $\left.\mathrm{mS} \cdot \mathrm{cm}^{-1}\right)$ and acidic ( $\mathrm{pH}$ slightly higher than 4$)$. It has a high organic matter content $\left(\mathrm{COD}_{0}\right.$ higher than $\left.8500 \mathrm{mg} \cdot \mathrm{L}^{-1}\right)$ including high concentrations of phenolic compounds $\left(\mathrm{C}_{0}\right)$. It can be also observed in this table that the performed membrane filtration hardly had significant influence on $\mathrm{pH}$ and conductivity of the samples. Even in NF, there was only a slight decrease in the conductivity since monovalent ions (sodium chloride) were hardly rejected. Regarding suspended solids, they were completely removed in both pre-treatments with membranes. Ultrafiltration treatment partially removed COD, total phenols and colour, from FTOP samples. With additional nanofiltration, the elimination percentages of these parameters increased.

From the analysis of samples by HPLC, the phenolic profile was determined. The results confirmed that hydroxytyrosol was the main phenolic compound in all samples, and the second one was tyrosol.

\subsection{Adsorption.}

\subsubsection{Phenols, COD and colour adsorption.}

Table 3 shows $\mathrm{pH}$ and conductivity in the liquid phase and COD, total phenols and colour removal percentages after 180 minutes of adsorption reaction, for all samples analysed and three resin dosage: 10, 20 and $40 \mathrm{~g} \cdot \mathrm{L}^{-1}$. The adsorption process was carried out in triplicate for each sample and resin dosage, and the standard deviation is presented in table 3 together with the average value. 
Table 3. Liquid phase characteristics at the end of adsorption $\left(180 \mathrm{~min}, 150 \mathrm{rpm}, 21 \pm 1^{\circ} \mathrm{C}\right)$. FTOP-1, FTOP-2, UF-1, UF-2 and NF-1 with three resin dosages: 10,20 and $40 \mathrm{~g} \cdot \mathrm{L}^{-1}$.

\begin{tabular}{lcccccc}
\hline \multirow{2}{*}{ Sample } & \multirow{2}{*}{$\begin{array}{c}\text { MN200 } \\
\left(\mathbf{g} \cdot \mathbf{L}^{-1}\right)\end{array}$} & $\mathbf{p H}^{(*)}$ & $\begin{array}{c}\text { Conductivity } \\
\left(\mathbf{m S} \cdot \mathbf{c m}^{-1}\right)\end{array}$ & & \multicolumn{3}{c}{ Removal (\%) } \\
\cline { 5 - 7 } & 10 & 4.8 & 80.8 & $59.8 \pm 3.3$ & $34.0 \pm 1.2$ & $76.6 \pm 1.1$ \\
FTOP-1 & 20 & 4.9 & 81.0 & $83.7 \pm 4.8$ & $39.2 \pm 0.8$ & $90.1 \pm 0.6$ \\
& 40 & 5.2 & 81.3 & $94.1 \pm 1.2$ & $44.6 \pm 1.9$ & $95.6 \pm 0.6$ \\
\hline \multirow{2}{*}{ FTOP-2 } & 10 & 4.5 & 81.4 & $82.1 \pm 3.7$ & $36.6 \pm 1.5$ & $74.6 \pm 0.3$ \\
& 20 & 4.7 & 81.1 & $93.2 \pm 2.3$ & $41.6 \pm 1.4$ & $71.3 \pm 0.7$ \\
& 40 & 4.9 & 82.5 & $97.3 \pm 2.8$ & $40.9 \pm 2.3$ & $76.9 \pm 1.0$ \\
\hline \multirow{2}{*}{ UF-1 } & 10 & 4.6 & 74.2 & $78.3 \pm 7.5$ & $32.2 \pm 3.9$ & $77.9 \pm 0.9$ \\
& 20 & 4.8 & 78.7 & $91.4 \pm 4.1$ & $38.7 \pm 3.0$ & $90.0 \pm 0.4$ \\
& 40 & 5.1 & 79.1 & $97.3 \pm 2.2$ & $43.7 \pm 3.9$ & $93.0 \pm 1.8$ \\
\hline \multirow{3}{*}{ UF-2 } & 10 & 4.5 & 85.1 & $87.4 \pm 5.6$ & $31.2 \pm 2.1$ & $84.0 \pm 2.6$ \\
& 20 & 4.7 & 85.6 & $95.4 \pm 1.8$ & $33.9 \pm 0.9$ & $91.8 \pm 0.7$ \\
& 40 & 5.0 & 83.9 & $98.3 \pm 2.3$ & $35.6 \pm 3.1$ & $95.4 \pm 1.1$ \\
\hline \multirow{2}{*}{ NF-1 } & 10 & 4.5 & 68.2 & $88.4 \pm 3.9$ & $34.2 \pm 0.8$ & $88.7 \pm 0.9$ \\
& 20 & 4.7 & 68.9 & $97.3 \pm 3.7$ & $38.5 \pm 0.2$ & $90.3 \pm 2.2$ \\
& 40 & 5.1 & 70.1 & $99.3 \pm 1.7$ & $40.3 \pm 2.0$ & $95.2 \pm 0.6$ \\
\hline
\end{tabular}

${ }^{(*)} \mathrm{pH}$ standard deviations were between 0.1 and 0.2

${ }^{(* *)}$ Conductivity standard deviations were between 0.2 and 1.4

As it can be seen in table 3, COD, total phenols and colour removal efficiencies increased with increasing MN200 dosage, because there was an increase in the amount of adsorption active sites. In all samples analysed after adsorption process $\mathrm{pH}$ and conductivity values were higher than the initial parameters. This phenomenon is due to the fact that MN200 is conditioned in $\mathrm{NaOH}$ solution (according to section 2.2), remaining a residual amount adhered in its surface. During the adsorption process $\mathrm{NaOH}$ was transferred into liquid phase; thereby $\mathrm{pH}$ and conductivity increased with increased MN200 dosage.

If FTOP-1/FTOP-2 and UF-1/UF-2 samples are compared, it is observed that total phenols initial concentration $\left(\mathrm{C}_{0}\right)$ was related to total phenols removal. As expected, for each resin 
dosage the phenols removal efficiencies increased with decreasing $\mathrm{C}_{0}$, since there was less solute for the same number of adsorption active sites.

Regarding the relationship between pre-treatments and adsorption process, it can be observed that the percentage of total phenols removed was very high independently from the pretreatment used. However, considering COD, which is a parameter that includes not only phenols but also other organic compounds, it can be verified that the NF-1 sample adsorbat had higher percentage of phenols and fewer impurities than the other samples.

In order to a better explanation of the results, the theoretical COD of the total phenols has been calculated. As total phenols are expressed in $\mathrm{mg} \mathrm{TY} \cdot \mathrm{L}^{-1}$ and the oxidation of $1 \mathrm{~mol}$ of tyrosol requires $9.5 \mathrm{~mol}$ of $\mathrm{O}_{2}$, i.e. $2.2 \mathrm{mg} \mathrm{O} \cdot \mathrm{mgTY}^{-1}$ are needed. The theoretical COD concentration of the total phenols adsorbed (CODPh.ads) has been presented in table 4. This parameter was calculated by the equation Eq.1:

$\mathrm{COD}_{\mathrm{Ph} . \mathrm{ads}}=\left(\mathrm{C}_{0}-\mathrm{C}_{\mathrm{e}}\right) \cdot 2.2=\mathrm{C}_{\mathrm{Ph} . \mathrm{ads}} \cdot 2.2$

where $\mathrm{C}_{0}$ was the initial total phenols concentration, and $\mathrm{C}_{\mathrm{e}}$ was the total phenols concentration in the liquid phase when equilibrium adsorption was achieved $\left(\mathrm{mg} T Y \cdot \mathrm{L}^{-1}\right)$. This difference is named $\mathrm{C}_{\mathrm{Ph} . \text { ads }}$ which was the total phenols concentration adsorbed in the resin $\left(\mathrm{mg} \mathrm{TY} \cdot \mathrm{L}^{-1}\right)$. In table 4 , the CODPh.ads in percentage, which was calculated by Eq.2, is also presented.

$\mathrm{COD}_{\text {Ph.ads }}(\%)=\frac{\mathrm{COD}_{\text {Ph.ads }}}{\mathrm{COD}_{\text {ads }}} \cdot 100$

where $\mathrm{COD}_{\text {ads }}$ was $\mathrm{COD}_{0}-\mathrm{COD}_{\mathrm{e}} \mathrm{COD}_{0}$ was the initial COD in the samples and $\mathrm{COD}_{\mathrm{e}}$ was the COD in the liquid phase in adsorption equilibrium. 
Table 4. Adsorption study of COD for three MN200 dosage (10, 20 and $\left.40 \mathrm{~g} \cdot \mathrm{L}^{-1}\right)$ at equilibrium for the FTOP-1, FTOP-2, UF-1, UF-2 and NF-1.

\begin{tabular}{ccccc}
\hline Sample & $\begin{array}{c}\text { MN200 } \\
\left(\mathbf{g} \cdot \mathbf{L}^{-\mathbf{1}}\right)\end{array}$ & $\begin{array}{c}\mathbf{C}_{\text {Ph.ads }} \\
\left(\mathbf{m g} \cdot \mathbf{L}^{-\mathbf{1}}\right)\end{array}$ & $\begin{array}{c}\mathbf{C O D} \\
\left(\mathbf{m g} \cdot \mathbf{L}^{-1}\right)\end{array}$ & $\begin{array}{c}\text { COD } \\
(\mathbf{\%})\end{array}$ \\
\hline \multirow{3}{*}{ FTOP-1 } & 10 & $606 \pm 33.4$ & $1333 \pm 73.5$ & $42.4 \pm 0.8$ \\
& 20 & $848 \pm 48.6$ & $1866 \pm 107.0$ & $47.6 \pm 1.8$ \\
& 40 & $953 \pm 12.2$ & $2097 \pm 26.7$ & $45.5 \pm 1.4$ \\
\hline \multirow{3}{*}{ FTOP-2 } & 10 & $649 \pm 29.3$ & $1428 \pm 64.4$ & $45.6 \pm 0.2$ \\
& 20 & $738 \pm 18.2$ & $1624 \pm 40.0$ & $45.5 \pm 0.4$ \\
& 40 & $770 \pm 22.1$ & $1694 \pm 48.7$ & $43.1 \pm 1.3$ \\
\hline \multirow{3}{*}{ UF-1 } & 10 & $748 \pm 67.7$ & $1646 \pm 149.0$ & $61.8 \pm 1.6$ \\
& 20 & $873 \pm 37.0$ & $1921 \pm 81.5$ & $60.1 \pm 2.0$ \\
& 40 & $930 \pm 19.9$ & $2047 \pm 43.7$ & $56.7 \pm 3.9$ \\
\hline \multirow{3}{*}{ UF-2 } & 10 & $631 \pm 40.4$ & $1388 \pm 89.0$ & $60.6 \pm 0.2$ \\
& 20 & $689 \pm 13.0$ & $1516 \pm 28.6$ & $61.3 \pm 0.5$ \\
& 40 & $710 \pm 16.6$ & $1561 \pm 36.5$ & $60.0 \pm 3.9$ \\
\hline \multirow{3}{*}{ NF-1 } & 10 & $627 \pm 27.7$ & $1379 \pm 60.9$ & $81.2 \pm 1.7$ \\
& 20 & $684 \pm 26.3$ & $1504 \pm 57.8$ & $78.7 \pm 2.6$ \\
& 40 & $705 \pm 12.1$ & $1551 \pm 26.6$ & $77.5 \pm 2.5$ \\
\hline
\end{tabular}

Although MN200 has high affinity for phenolic compounds, this resin adsorbs other substances present in the aqueous phase. With nanofiltration it can be observed that the remaining non-phenolic COD after pre-treatment hardly compete on the resin active sites with phenols, enhancing the adsorption of the phenolic compounds.

\subsubsection{Kinetics of phenol adsorption.}

Figure 1 shows the amount of total phenols adsorbed per $g$ of MN200 resin $\left(q_{t}\right.$ in $\left.\mathrm{mg} \cdot \mathrm{g}^{-1}\right)$ through the adsorption time, for three resin concentrations: figure 1a) $10 \mathrm{~g} \cdot \mathrm{L}^{-1}$, figure $1 \mathrm{~b}$ ) 20 $\mathrm{g} \cdot \mathrm{L}^{-1}$ and figure 1c) $40 \mathrm{~g} \cdot \mathrm{L}^{-1}$. 
a) $10 \mathrm{~g} / \mathrm{L}$

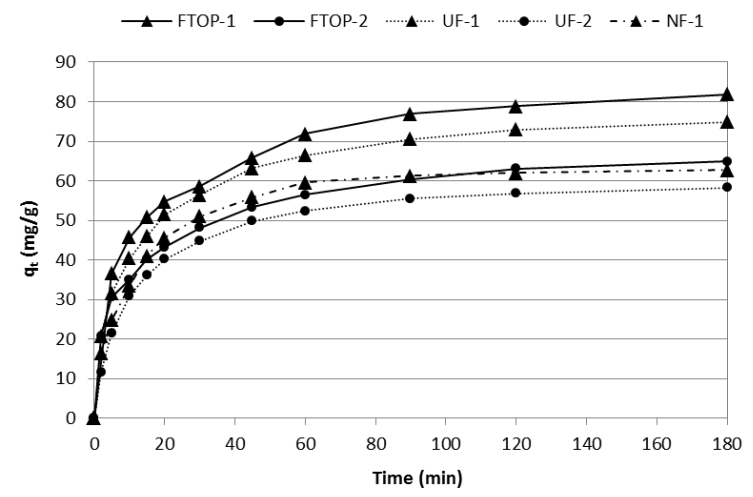

b) $20 \mathrm{~g} / \mathrm{L}$

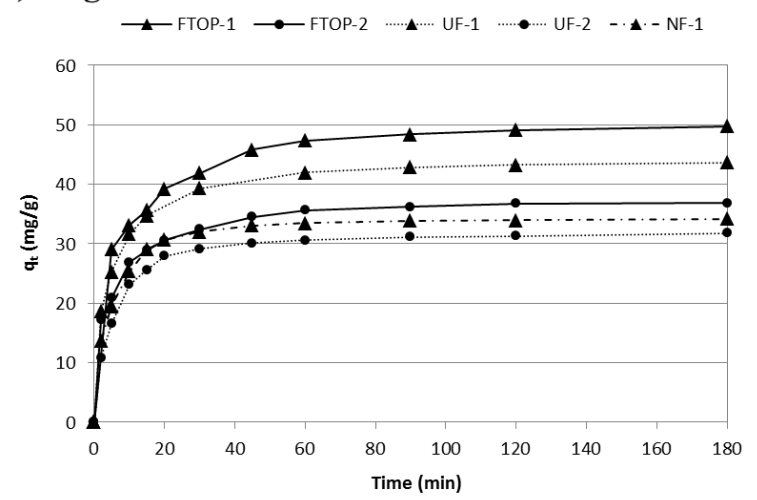

c) $40 \mathrm{~g} / \mathrm{L}$

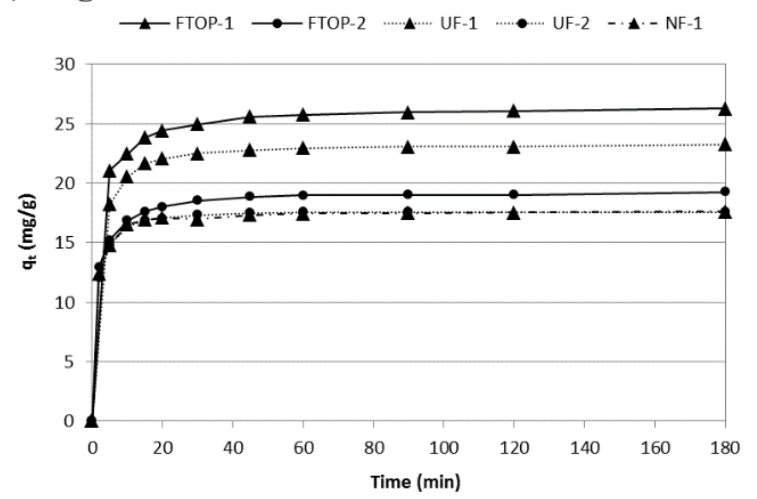

Figure 1. Adsorbed amounts of total phenols as a function of time in FTOP-1, FTOP-2, UF-1, UF-2 and NF-1 for three resin dosages: figure 1a) $10 \mathrm{~g} \cdot \mathrm{L}^{-1}$, figure $\left.1 \mathrm{~b}\right) 20 \mathrm{~g} \cdot \mathrm{L}^{-1}$ and figure $1 \mathrm{c}$ ) $40 \mathrm{~g} \cdot \mathrm{L}^{-1}$.

It can be observed that adsorption was very fast during the first minutes, because there were a lot of adsorption active sites in the resin. Then, adsorption becomes slower near the 
equilibrium. As expected, initial adsorption was faster as MN200 concentration increased, and the equilibrium was achieved earlier.

\subsubsection{Pseudo first-order and pseudo second-order.}

The kinetic parameters are helpful for the prediction of adsorption rate, which gives important information for designing and modelling the processes. Adsorption kinetics of phenolic compounds was studied through the testing of Lagergren (1898) and pseudo secondorder $^{36}$ and pseudo second-order ${ }^{37}$ models, in order to find correlations between adsorbed amounts and reaction time. Linear forms of Lagergren (pseudo frist-order kinetic) and pseudo-second order kinetic equations are given in Eq.3 and Eq.4, respectively:

$$
\begin{aligned}
& \ln \left(\mathrm{q}_{\mathrm{e}}-\mathrm{q}_{\mathrm{t}}\right)=\ln \mathrm{q}_{\mathrm{e}}-\mathrm{k}_{1} \cdot \mathrm{t} \\
& \frac{\mathrm{t}}{\mathrm{q}_{\mathrm{t}}}=\frac{1}{\mathrm{k}_{2} \cdot \mathrm{q}_{\mathrm{e}}^{2}}+\frac{1}{\mathrm{q}_{\mathrm{e}}} \cdot \mathrm{t}
\end{aligned}
$$

where $\mathrm{k}_{1}\left(\mathrm{~min}^{-1}\right)$ is the kinetic constant of pseudo first-order, $\mathrm{k}_{2}\left(\mathrm{~g} \cdot \mathrm{mg}^{-1} \cdot \mathrm{min}^{-1}\right)$ is rate constant of pseudo second-order, and $\mathrm{q}_{\mathrm{e}}$ and $\mathrm{q}_{\mathrm{t}}\left(\mathrm{mg} \cdot \mathrm{g}^{-1}\right)$ are the amounts of adsorbed phenol at equilibrium and at time $\mathrm{t}(\mathrm{min})$, respectively. Table 5 summarizes the parameters derived from the application of Eq.3 and Eq.4 for phenols adsorption, in all samples analysed and the three resin dosages: $10 \mathrm{~g} \cdot \mathrm{L}^{-1}, 20 \mathrm{~g} \cdot \mathrm{L}^{-1}$ and $40 \mathrm{~g} \cdot \mathrm{L}^{-1}$. 
Table 5. Kinetic parameters for phenols adsorption in FTOP-1, FTOP-2, UF-1, UF-2 and NF-1 for three MN200 dosage; 10, 20 and $40 \mathrm{~g} \cdot \mathrm{L}^{-1}$.

\begin{tabular}{|c|c|c|c|c|c|c|c|}
\hline \multirow[b]{2}{*}{ Sample } & \multirow{2}{*}{$\begin{array}{c}\text { MN200 } \\
\left(\mathrm{g} \cdot \mathbf{L}^{-1}\right)\end{array}$} & \multicolumn{3}{|c|}{ Pseudo first-order } & \multicolumn{3}{|c|}{ Pseudo second-order } \\
\hline & & $\begin{array}{c}\mathbf{q}_{\mathrm{e}} \\
(\mathrm{mg} / \mathrm{g})\end{array}$ & $\begin{array}{c}\mathbf{k}_{1} \times 10^{2} \\
\left(\mathbf{m i n}^{-1}\right)\end{array}$ & $\mathbf{R}^{2}$ & $\begin{array}{c}\mathbf{q e}_{(\mathrm{e}} \\
(\mathrm{mg} / \mathrm{g})\end{array}$ & $\begin{array}{c}\mathbf{k}_{2} \times 10^{3} \\
\left(\mathrm{~g} \cdot \mathrm{mg}^{-1} \cdot \mathrm{min}^{-1}\right)\end{array}$ & $\mathbf{R}^{2}$ \\
\hline \multirow{3}{*}{ FTOP-1 } & 10 & 58.36 & 3.91 & 0.9596 & 66.67 & 0.88 & 0.9806 \\
\hline & 20 & 40.79 & 4.86 & 0.9004 & 43.48 & 2.25 & 0.9918 \\
\hline & 40 & 16.26 & 6.15 & 0.9295 & 24.27 & 10.05 & 0.9995 \\
\hline \multirow{3}{*}{ FTOP-2 } & 10 & 61.68 & 5.12 & 0.8551 & 66.23 & 1.74 & 0.9962 \\
\hline & 20 & 21.71 & 0.83 & 0.7502 & 37.88 & 6.39 & 0.9996 \\
\hline & 40 & 2.91 & 4.01 & 0.8770 & 19.27 & 42.22 & 1.0000 \\
\hline \multirow{3}{*}{ UF-1 } & 10 & 72.56 & 5.30 & 0.8824 & 77.52 & 1.44 & 0.9980 \\
\hline & 20 & 26.10 & 5.92 & 0.9538 & 44.64 & 5.97 & 0.9999 \\
\hline & 40 & 4.12 & 5.71 & 0.9794 & 23.36 & 35.16 & 1.0000 \\
\hline \multirow{3}{*}{ UF-2 } & 10 & 57.41 & 5.39 & 0.5424 & 61.35 & 1.64 & 0.9996 \\
\hline & 20 & 17.25 & 5.93 & 0.9560 & 32.47 & 7.93 & 0.9999 \\
\hline & 40 & 2.17 & 4.55 & 0.8953 & 17.79 & 65.12 & 1.0000 \\
\hline \multirow{3}{*}{ NF-1 } & 10 & 61.60 & 6.03 & 0.9514 & 66.67 & 1.76 & 0.9991 \\
\hline & 20 & 14.69 & 5.76 & 0.9843 & 34.97 & 9.01 & 0.9999 \\
\hline & 40 & 2.18 & 4.53 & 0.9248 & 17.67 & 68.16 & 1.0000 \\
\hline
\end{tabular}

According to the data from table 5, the calculated $\mathrm{q}_{\mathrm{e}}$ amounts applying the Pseudo first-order kinetic model do not give reasonable values, since they were lower than the expected ones according to the experimental data. This can be observed in figure 1 where the experimental data have been represented. Besides, the $\mathrm{R}^{2}$ obtained from the Pseudo second-order kinetic was better than those obtained from the Pseudo first-order one. These values were above 0.98 in all cases, and the calculated $\mathrm{q}_{\mathrm{e}}$ values were closer to the experimental data. Hence, phenols adsorption with MN200 can be approximated more favourably by the Pseudo second-order model. These results agree with previous studies reported by others authors for phenols adsorption with MN200. ${ }^{38,39}$ The kinetic constant $\mathrm{k}_{2}$ was related with $\mathrm{C}_{0}$. In table 5 it can be seen that $\mathrm{k}_{2}$ increased when $\mathrm{C}_{0}$ decreased. 


\subsubsection{Intra-particle diffusion model.}

Phenols adsorption process can be controlled by one or more steps: film or external diffusion, pore diffusion, surface diffusion and adsorption on the pore surface, or a combination of more than one step. ${ }^{40}$ The intra-particle diffusion model relates the amount adsorbed at time by the Eq.5:

$\mathrm{q}_{\mathrm{t}}=\mathrm{k}_{\mathrm{id}} \cdot \mathrm{t}^{1 / 2}+\theta$

where $\mathrm{k}_{\mathrm{id}}$ is the intra-particle diffusion rate constant $\left(\mathrm{mg} \cdot \mathrm{g}^{-1} \cdot \mathrm{min}^{-1}\right)$, and $\theta\left(\mathrm{mg} \cdot \mathrm{g}^{-1}\right)$ is a constant related to the thickness of the boundary layer: the larger is the value of $\theta$, the greater is the boundary layer effect. ${ }^{41}$ As an example, in figure 2 the plot of $\mathrm{q}_{\mathrm{t}}$ versus $\mathrm{t}^{1 / 2}$ for NF-1 and three dosages MN200 (10, 20 and $\left.40 \mathrm{~g} \cdot \mathrm{L}^{-1}\right)$ is shown.

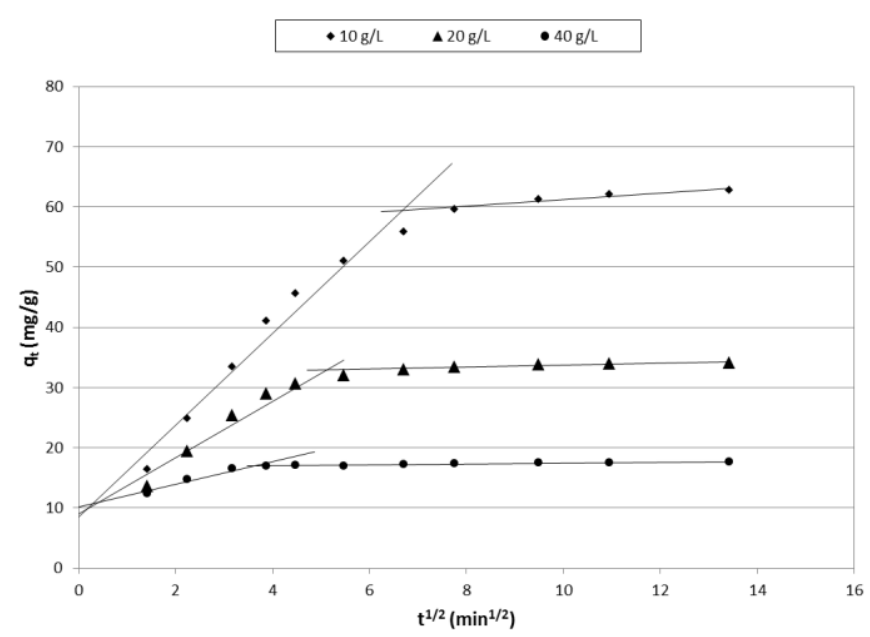

Figure 2. Intra-particle diffusion model from NF-1with 10,20 and $40 \mathrm{~g} \cdot \mathrm{L}^{-1}$ of the $\mathrm{MN200}$.

It can be observed that the data do not fit to a straight line and exhibit multi-linear plots. Thus, the sorption process is not only controlled by intra-particle diffusion, and external resistance to mass transfer is important in the first steps of adsorption. This is the reason why 
there was a deviation of straight lines from the origin. Besides, this initial period shows a slight curvature, usually attributed to boundary layer diffusion effects or external mass transfer effects. ${ }^{40}$ For all samples and resin dosage analysed (data not shown) the data points are related by two straight lines, as seen in figure 2 . This agrees with studies reported by Valderrama et al. (2010) about phenol adsorption in liquid phase by MN200. ${ }^{38}$ In figure 2 it can be observed that the adsorption equilibrium was achieved faster when the resin concentration increased.

\subsubsection{Adsorption isotherms.}

Several models have been reported in papers to describe experimental data of adsorption isotherms, but the most frequently used were the Langmuir and Freundlich isotherms. The Langmuir model assumes a uniform surface and a single layer of adsorbed material ${ }^{38}$ unlike Freundlich isotherm that assumes that adsorption is heterogeneous and there is not only a layer of adsorbed material. ${ }^{42}$ The linear form of Langmuir and Freundlich isotherms equations are given in Eq.6 and Eq.7, respectively:

$$
\begin{aligned}
& \frac{\mathrm{C}_{\mathrm{e}}}{\mathrm{q}_{\mathrm{e}}}=\frac{1}{\mathrm{~K}_{\mathrm{L}} \cdot \mathrm{q}_{0}}+\frac{1}{\mathrm{q}_{0}} \cdot \mathrm{C}_{\mathrm{e}} \\
& \ln \mathrm{q}_{\mathrm{e}}=\ln \mathrm{K}_{\mathrm{f}}+\frac{1}{\mathrm{n}} \cdot \ln \mathrm{C}_{\mathrm{e}}
\end{aligned}
$$

where $C_{e}\left(m g \cdot L^{-1}\right)$ is the total phenols concentration at the equilibrium, $\mathrm{q}_{e}\left(\mathrm{mg} \cdot \mathrm{g}^{-1}\right)$ is the total phenols mass adsorbed at the equilibrium per $\mathrm{g}$ of $\mathrm{MN} 200, \mathrm{q}_{0}\left(\mathrm{mg} \cdot \mathrm{g}^{-1}\right)$ is the maximal adsorption capacity and $\mathrm{K}_{\mathrm{L}}\left(\mathrm{L} \cdot \mathrm{mg}^{-1}\right)$ is the Langmuir coefficient. In the Freundlich equation $\mathrm{K}_{\mathrm{f}}\left(\mathrm{mg} \cdot \mathrm{g}^{-1}\right) \cdot\left(\mathrm{mg} \cdot \mathrm{L}^{-1}\right)^{-1 / \mathrm{n}}$ and $\mathrm{n}$ are empirical coefficients. $\mathrm{K}_{\mathrm{F}}$ indicates the adsorption capacity 
and $\mathrm{n}$ is related with the adsorption intensity. Thus, $\mathrm{n}$ higher than 1 means that the operating conditions are appropriate for the adsorption. ${ }^{40}$ Both isotherms were performed for all samples and five resin dosage $\left(5,10,20,30\right.$ and $\left.40 \mathrm{~g} \cdot \mathrm{L}^{-1}\right)$. The fitted parameter values are listed in table 6.

Table 6. Isotherm parameters for total phenols adsorption in FTOP-1, FTOP-2, UF-1, UF-2 and NF-1 on MN200 resin at room temperature $\left(21 \pm 1^{\circ} \mathrm{C}\right)$

\begin{tabular}{|c|c|c|c|c|c|c|c|}
\hline \multirow[b]{2}{*}{ Sample } & \multicolumn{4}{|c|}{ Langmuir } & \multicolumn{3}{|c|}{ Freundlich } \\
\hline & $\begin{array}{c}\mathbf{K}_{\mathbf{L}} \\
\left(\mathbf{L} \cdot \mathbf{m g}^{-1}\right)\end{array}$ & $\begin{array}{c}\mathbf{q}_{0} \\
\left(\mathbf{m g} \cdot \mathbf{g}^{-1}\right)\end{array}$ & $\mathbf{R}_{\mathbf{L}}$ & $\mathbf{R}^{2}$ & $\begin{array}{c}\mathbf{K}_{\mathbf{f}} \\
\left(\mathbf{m g} \cdot \mathbf{g}^{-1}\right) \cdot\left(\mathbf{m g} \cdot \mathbf{L}^{-1}\right)^{-1 / n}\end{array}$ & $\mathbf{n}$ & $\mathbf{R}^{2}$ \\
\hline FTOP-1 & 0.0054 & 78.13 & 0.156 & 0.9987 & 2.87 & 2.05 & 0.9973 \\
\hline FTOP-2 & 0.0073 & 107.53 & 0.147 & 0.9989 & 3.25 & 1.82 & 0.9810 \\
\hline UF-1 & 0.0056 & 85.47 & 0.165 & 0.9992 & 2.42 & 1.84 & 0.9993 \\
\hline UF-2 & 0.0081 & 129.87 & 0.146 & 0.9986 & 3.10 & 1.63 & 0.9863 \\
\hline NF-1 & 0.0154 & 117.75 & 0.084 & 0.9941 & 4.10 & 1.68 & 0.9881 \\
\hline
\end{tabular}

Assessing $\mathrm{R}^{2}$ value, it is observed that the data obtained from the adsorption tests fitted to Langmuir equation better than to Freundlich equation. These results are consistent with those reported by Caetano et al. (2009) for phenols adsorption with the MN200 resin. ${ }^{39}$ It can be seen in table 6 that $\mathrm{K}_{\mathrm{L}}$ increased with decreased initial phenol concentration in the solution $\left(\mathrm{C}_{0}\right)$. This parameter is related to the efficiency of phenols adsorption and to the dimensionless equilibrium parameter $\mathrm{R}_{\mathrm{L}}$, through the Eq.8:

$$
\mathrm{R}_{\mathrm{L}}=\frac{1}{1+\mathrm{K}_{\mathrm{L}} \cdot \mathrm{C}_{0}}
$$

The phenol adsorption is considered as irreversible when $\mathrm{R}=0$, favourable when $0<\mathrm{R}<1$ and unfavourable when $\mathrm{R}>1 .{ }^{40}$ The $\mathrm{R}_{\mathrm{L}}$ values are presented in table 6 , where it can be 
observed that $\mathrm{R}_{\mathrm{L}}$ always was between 0 and 1 . The NF-1 presented the lowest $\mathrm{R}_{\mathrm{L}}$, which showed the best conditions for adsorption.

\subsection{Desorption.}

\subsubsection{Organic solvent selection.}

Phenols desorption efficiencies achieved for ethanol and ethyl acetate as liquid phase (according to the protocol in 2.5 .1 section) were 87.3 and $91.8 \%$, respectively. Phenols desorption was very fast in the first minutes. At 5 minutes the 85.8 and $80.5 \%$ of total phenols were recovered by the ethanol and ethyl acetate, respectively. In view of these results, and considering higher toxicity and price for the ethyl acetate in comparison with ethanol, ethanol was selected for performing the desorption experiments.

\subsubsection{Phenols recovery.}

In figure 3 , the percentage of total phenols recovered by desorption is presented, for all samples analysed in 3.2.3 section and the three resin dosages (10, 20 and $\left.40 \mathrm{~g} \cdot \mathrm{L}^{-1}\right)$.

It can be observed that desorption was again very fast in the first minutes for all the cases surveyed, and evolved quickly toward equilibrium. Phenols desorption equilibrium was achieved after 15 minutes in all the experiments performed. There were no relation between phenols recovery and the MN200 dosage. 
a) $10 \mathrm{~g} / \mathrm{L}$

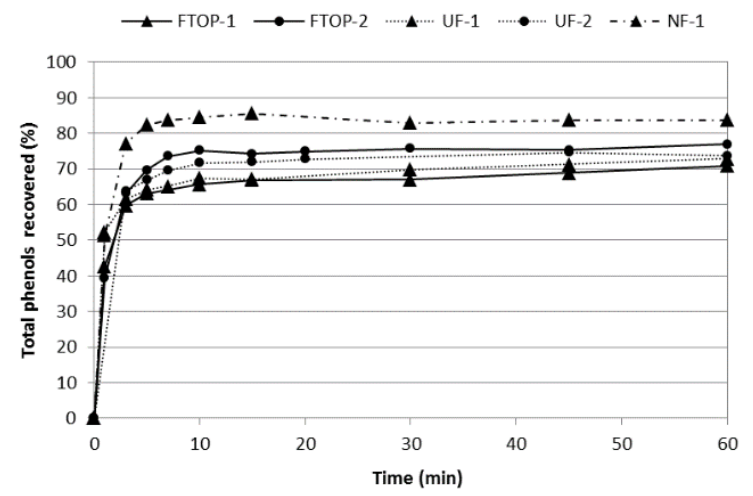

b) $20 \mathrm{~g} / \mathrm{L}$

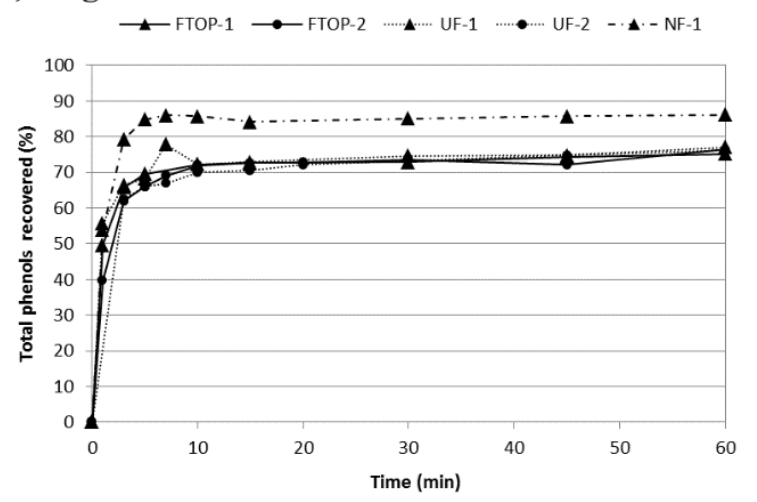

c) $40 \mathrm{~g} / \mathrm{L}$

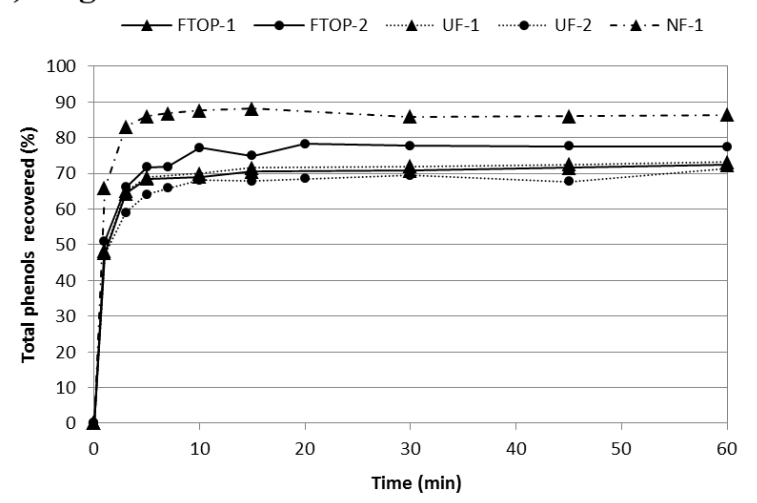

Figure 3. Percentage of total phenols recovered in desorption process from FTOP-1, FTOP-2, UF-1, UF-2 and NF-1, and three MN200 dosages; a) $10 \mathrm{~g} \cdot \mathrm{L}^{-1}$, b) $20 \mathrm{~g} \cdot \mathrm{L}^{-1}$ and c) $40 \mathrm{~g} \cdot \mathrm{L}^{-1}$.

Nevertheless, the percentage of total phenols recovered was related with FTOP pre-treatment performed. For FTOP and UF samples, phenols concentration in ethanol phase were between $71-77 \%$, while this amount increased near $85 \%$ for NF-1. As commented in adsorption section, the solutes adsorbed from NF-1 had a higher phenols percentage. Therefore, there were fewer impurities retained in the resin, and phenol desorption was easier. 
The phenolic profile of NF-1 performed by HPLC is presented in figure 4 . In this figure, the following chromatograms are compared: initial NF-1 sample (graph on the top of the figure), NF-1 after adsorption with $40 \mathrm{~g} \cdot \mathrm{L}^{-1}$ of MN200 (graph in the middle part of the figure), and ethanol after desorption process (at the bottom).
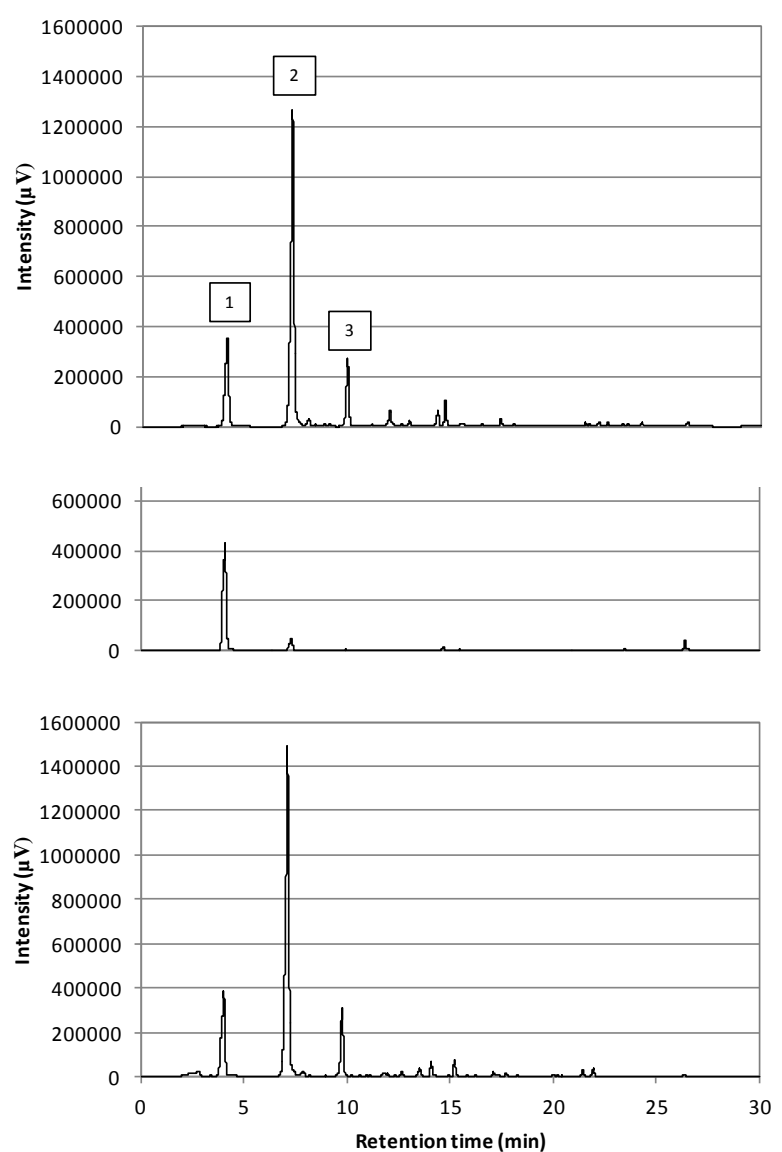

Figure 4. HPLC chromatograms of the polyphenols in: NF-1 (on top), NF-1 after adsorption by $40 \mathrm{~g} \cdot \mathrm{L}^{-1}$ of MN200 (in the middle), and ethanol after desorption process (at the bottom). Peak identification: (1) Hidroquinone (internal standard); (2) Hydroxytyrosol; (3) Tyrosol.

As it can be seen in figure 4, after adsorption TY was completely removed from NF-1, and only a few amount of HTY was detected. Regarding chromatogram after desorption, it was observed that the phenolic profile was practically the same as the initial one. 


\subsection{Useful life of MN200.}

Ten operating cycles have been carried out with FTOP-2, UF-2 and NF-1. These three samples had similar $\mathrm{C}_{0}$, whereby the influence of FTOP pre-treatment in the useful life of MN200 was studied. Throughout experiments, it can be stated that both phenols adsorption and desorption capacities of MN200 decreased with its use. In table 7 the results for the first and latest adsorption and desorption operating cycles are shown.

Table 7. Adsorption and desorption phenols percentage for the first and latest cycle carried out in the useful life of MN200 study.

\begin{tabular}{ccccccccc}
\hline \multirow{3}{*}{ Sample } & \multicolumn{2}{c}{ Adsorption phenols (\%) } & & \multicolumn{3}{c}{ Desorption phenols (\%) } \\
\cline { 2 - 4 } \cline { 6 - 8 } & $\begin{array}{c}\mathbf{1}^{\mathbf{0}} \\
\text { cycle }\end{array}$ & $\begin{array}{c}\mathbf{1 0}^{\mathbf{0}} \\
\text { cycle }\end{array}$ & $\begin{array}{c}\text { Lost efficiency } \\
\text { in 10 cycles }\end{array}$ & & $\begin{array}{c}\mathbf{1}^{\mathbf{0}} \\
\text { cycle }\end{array}$ & $\begin{array}{c}\mathbf{1 0}^{\mathbf{0}} \\
\text { cycle }\end{array}$ & $\begin{array}{c}\text { Lost efficiency } \\
\text { in 10 cycles }\end{array}$ \\
\hline FTOP-2 & 95.8 & 87.9 & 7.9 & & 81.8 & 69.7 & 12.1 \\
UF-2 & 97.4 & 96.5 & 0.9 & & 84.8 & 76.3 & 8.5 \\
NF-1 & 98.2 & 97.4 & 0.8 & & 91.7 & 87.2 & 4.5 \\
\hline
\end{tabular}

After ten operating cycles it can be observed that adsorption and desorption phenols performance decreased, but the loss of efficiency through desorption was higher than in the adsorption process. The effect of pre-treatment carried out was very important in the useful life of MN200. It can be seen in table 7 that the greatest diminution in adsorption and desorption efficiencies occurred for FTOP-2. This can be explained due to the suspended solids and fats in FTOP-2, which caused fouling in resin surface clogging the resin pores.

\section{CONCLUSIONS.}

Fermentation brines from table olive processing are characterized by containing valuable phenolic compounds, including hydroxytyrosol, which shows the most antioxidant capacity. In this work, the separation of phenols from fermentation brines from table olive processing has been evaluated, and the nonionic polymeric resin MN200 was selected. 
The results have been achieved for raw FTOPs samples and for ultrafiltrated and nanofiltrated streams. Phenols adsorption from all the samples tested has fitted properly to a pseudo-second order kinetics and the process can be described by the Langmuir isotherm model. The equilibrium is achieved in approximately 90 and $60 \min$ for 20 and $40 \mathrm{~g} \cdot \mathrm{L}^{-1}$, respectively. Phenol removal efficiencies higher than $90 \%$ have been achieved when these resin concentrations have been used. Phenols transport from the solution to the MN200 surface is shown to occur according to two steps: the first step is due to external resistance to mass transfer, and the second one being related to micropore diffusion.

Results have indicated that the adsorption of the most exhaustively pretreated effluent has separated phenols more selectively. Only around $22 \%$ of the non-phenolic organic matter has been separated together with phenols in NF-1 sample.

Desorption with ethanol was successful, in such a way that more than $85 \%$ of phenolic compounds were recovered from the resin independently from the resin concentration in the case of nanofiltered FTOP (NF-1).

Finally, the evaluation of ten operation cycles (adsorption + desorption) drives to establish that the adsorption capacity of the resin hardly decrease, meanwhile desorption efficiency decreases at a higher extent, except for the case of NF-1.

\section{Acknowledgments.}

The authors of this work thank the financial support of CDTI (Centre for Industrial Technological Development) depending on the Spanish Ministry of Science and Innovation. 


\section{References.}

1. Erlund I, Review of the flavonoids quercetin, hesperetin, and naringenin. Dietary sources, bioactivities, bioavailability, and epidemiology. Nutr Res 24:851-874 (2004).

2. Odeh RM, Cornish LA, Natural antioxidants for the prevention of atherosclerosis. Pharmacotherapy 15:648-659 (1995).

3. Seifried EH, Anderson DE, Fisher EI and Milner JA, A review of the interaction among dietary antioxidants and reactive oxygen species. J Nutr Biochem 18:567-579 (2007).

4. Garcia-Castello E, Cassano A, Criscuoli A, Conidi C and Drioli E, Recovery and concentration of polyphenols from olive mill wastewaters by integrated membrane system. Water Res 44:3883-3892 (2010).

5. Fki I, Allouche N and Sayadi S, The use of polyphenolic extract, purified hydroxytyrosol and 3,4-dihydroxyphenyl acetic acid from olive mill wastewater for the stabilization of refined oils: A potential alternative to synthetic antioxidants. Food Chem 93:197-204 (2005).

6. Tuck KL and Hayball PJ, Major phenolic compounds in olive oil: Metabolism and health effects. J Nutr Biochem 13:636-644 (2002).

7 Sabatini N, Recent Patenets in Olive Oil Industry: New technologies for the recovery of phenols compounds from olive oil, olive oil industrial by-products and wastewaters. Nutr Agric Food 2:154-159 (2010).

8. Bouaziz M, Lassoued S, Bouallagui Z, Smaoui S, Gargoubi A, Dhouib A and Sayadi S, Synthesis and recovery of high bioactive phenolics from table-olive brine process wastewater. Bioorganic Med Chem 16:9238-9246 (2008). 
9. Malheiro R, Sousa A, Casal S, Bento A and Pereira JA, Cultivar effect on the phenolic composition and antioxidant potential of stoned table olives. Food Chem Toxicol 49:450-457 (2011).

10. ASEMESA. Asociación de Exportadores e Industriales de Aceitunas de Mesa. (Accessed December 2014 at [http://www.asemesa.es/content/datos_generales_del_sector]).

11. Marsilio V and Lanza B, Characterisation of an oleuropein degrading strain of Lactobacillus plantarum. Combined effects of compounds present in olive fermenting brines (phenols, glucose and $\mathrm{NaCl}$ ) on bacterial activity. J Sci Food Agric 76:520-524 (1998).

12. Ben Othman N, Roblain D, Chammen N, Thonart P and Hamdi M, Antioxidant phenolic compounds loss during the fermentation of Chétoui olives. Food Chem 116:662-669 (2009).

13. Brenes M, Rejano L, Garcia P, Sanchez A and Garrido A, Biochemical changes in phenolic compounds during Spanish-Style green olive processing. J Agric Food Chem 43:2702-2706 (1995).

14. Fendri I, Chamkha M, Bouaziz M, Labat M, Sayadi S and Abdelkafi S, Olive fermentation brine: biotechnological potentialities and valorization. Environ Technol 34:1-13 (2013).

15. Romero-Barranco C, Brenes-Balbuena M, García-García P and Garrido-Fernández A, Management of spent brines or osmotic solutions. J Food Eng 49:237-246 (2001).

16. Miralles P, Chisvert A, Salvador A, Determination of hydroxytyrosol and tyrosol by liquid chromatography for the quality control of cosmetic products based on olive extracts. J Pharm Biomed Anal 102:157-161 (2015). 
17. Kopsidas GC, Wastewaters from the preparation of table olives. Water Res 26:629-631 (1992).

18. Garrido-Fernández A, Brenes-Balbuena M and García-García P, Treatment of brine fermentation of green olives. Int J fats Oils 3:291-298 (1992).

19. Reid E, Liu X and Judd SJ, Effect of high salinity on activated sludge characteristics and membrane permeability in an immersed membrane bioreactor. J Memb Sci 283:164-171 (2006).

20. García-García P, López-López A, Moreno-Baquero JM and Garrido-Fernández A, Treatment of wastewaters from the green table olive packaging industry using electrocoagulation. Chem Eng J 170:59-66 (2011).

21. Kiril-Mert B, Yonar T, Yalili-Kiliç M and Kestioğlu K, Pre-treatment studies on olive oil mill effluent using physicochemical, Fenton and Fenton-like oxidations processes. $J$ Hazard Mater 174:122-128 (2010).

22. Zirehpour A, Jahanshahi M and Rahimpour A, Unique membrane process integration for olive oil mill wastewater purification. Sep Purif Technol 96:124-131 (2012).

23. Cassano A, Conidi C and Drioli E, Comparison of the performance of UF membranes in olive mill wastewaters treatment. Water Res 45:3197-3204 (2011).

24. Stavropoulos GG, Samaras P and Sakellaropoulos GP, Effect of activated carbons modification on porosity, surface structure and phenol adsorption. J Hazard Mater 151:414-421 (2008). 
25. Soto ML, Moure A, Domínguez H and Parajó JC, Recovery, concentration and purification of phenolic compounds by adsorption: A review. J Food Eng 105:1-27 (2011).

26. Michailof C, Stavropoulos GG and Panayiotou C, Enhanced adsorption of phenolic compounds, commonly encountered in olive mill wastewaters, on olive husk derived activated carbons. Bioresour Technol 99:6400-6408 (2008).

27. Aly AA, Hasan NY and Al-Farraj AS, Olive mill wastewater treatment using a simple zeolite-based low-cost method. J Environ Manage 145:341-348 (2014).

28. Ali I, Asim M and Khan T, Low cost adsorbents for the removal of organic pollutants from wastewater. J Environ Manage 113:170-183 (2012).

29. Ipek IY, Kabay N, Yüksel M, Yapici D and Yüksel Ü, Application of adsorptionultrafiltration hybrid method for removal of phenol from water by hypercrosslinked polymer adsorbents. Desalination 306:24-28 (2012).

30. Ipek IY, Yüksel S, Kabay $\mathrm{N}$ and Yüksel M, Investigation of process parameters for removal of bisphenol A (BPA) from water by polymeric adsorbents in adsorptionultrafiltration hybrid system, J Chem Technol Biotechnol 89:835-840 (2014).

31. Busca G, Berardinelli S, Resini C and Arrighi L, Technologies for the removal of phenol from fluid streams: A short review of recent developments. J Hazard Mater 160:265$288(2008)$.

32. APHA AWWA WEF. Standard Methods for the Examination of Water and Wastewater, 21st ed. American Public Health Association, Washington DC, USA (2005). 
33. Castro A and Brenes M, Fermentation of washing waters of spanish-style green olive processing. Process Biochem 36:797-802 (2011).

34. Singleton V, Orthofer R and Lamuela-Raventós RM, Analysis of total phenols and other oxidation substrates and antioxidants by means of Folin-Ciocalteu reagent. Methods Enzymol 299:152-178 (1999).

35. El- Abbassi A, Khayet M and Hafidi A, Micellar enhanced ultrafiltration process for the treatment of olive mill wastewater. Water Res 45:4522-4530 (2011).

36. Lagergren S, About the theory of so called adsorption of solute substances. Ksver Veterskapsakad Handl 24:1-6 (1898).

37. Ho YS and McKay G, Pseudo-second order model for sorption processes. Process Biochem 34:451-465 (1999).

38. Valderrama C, Barios JI, Caetano M, Farran A and Cortina JL, Kinetic evaluation of phenol/aniline mixtures adsorption from aqueous solutions onto activated carbon and hypercrosslinked polymeric resin (MN200). React Funct Polym 70:142-150 (2010).

39. Caetano M, Valderrama C, Farran A and Cortina JL, Phenol removal from aqueous solution by adsorption and ion exchange mechanisms onto polymeric resins. J Colloid Interface Sci 338:402-409 (2009).

40. Fierro V, Torné-Fernández V, Montané D and Celzard A, Adsorption of phenol onto activated carbons having different textural and surface properties. Microporous $M$ esoporous Mater 111:276-284 (2008).

41. Weber WJ Jr and Morris JC, Kinetics of Adsorption on Carbon from Solution. J Sanit Eng Div 89:31-60 (1963). 
42. Mohd AT, Hameed BH and Ahmad AL, Batch adsorption of phenol onto physiochemical-activated coconut shell. J Hazard Mater 161:1522-1529 (2009).

\section{Figures.}

Figure 1. Adsorbed amounts of total phenols as a function of time in FTOP-1, FTOP-2, UF1, UF-2 and NF-1 for three resin dosages: figure 1a) $10 \mathrm{~g} \cdot \mathrm{L}^{-1}$, figure $\left.1 \mathrm{~b}\right) 20 \mathrm{~g} \cdot \mathrm{L}^{-1}$ and figure 1c) $40 \mathrm{~g} \cdot \mathrm{L}^{-1}$.

Figure 2. Intra-particle diffusion model from NF-1 with 10, 20 and $40 \mathrm{~g} \cdot \mathrm{L}^{-1}$ of the MN200.

Figure 3. Percentage of total phenols recovered in desorption process from FTOP-1, FTOP2, UF-1, UF-2 and NF-1, and three MN200 dosages; a) $10 \mathrm{~g} \cdot \mathrm{L}^{-1}$, b) $20 \mathrm{~g} \cdot \mathrm{L}^{-1}$ and c) $40 \mathrm{~g} \cdot \mathrm{L}^{-1}$.

Figure 4. HPLC chromatograms of the polyphenols in: NF-1 (on top), NF-1 after adsorption by $40 \mathrm{~g} \cdot \mathrm{L}^{-1}$ of MN200 (in the middle), and ethanol after desorption process (at the bottom).

Peak identification: (1) Hidroquinone (internal standard); (2) Hydroxytyrosol; (3) Tyrosol.

\section{Tables.}

Table 1. Physical and chemical characteristics (data from supplier).

Table 2. Wastewaters characterization. 
Table 3. Liquid phase characteristics at the end of adsorption (180 min, $\left.150 \mathrm{rpm}, 21 \pm 1^{\circ} \mathrm{C}\right)$. FTOP-1, FTOP-2, UF-1, UF-2 and NF-1 with three resin dosages: 10, 20 and $40 \mathrm{~g} \cdot \mathrm{L}^{-1}$. Table 4. Adsorption study of COD for three MN200 dosage (10, 20 and $\left.40 \mathrm{~g} \cdot \mathrm{L}^{-1}\right)$ at equilibrium for the FTOP-1, FTOP-2, UF-1, UF-2 and NF-1.

Table 5. Kinetic parameters for phenols adsorption in FTOP-1, FTOP-2, UF-1, UF-2 and NF-1 for three MN200 dosage; 10, 20 and $40 \mathrm{~g} \cdot \mathrm{L}^{-1}$.

Table 6. Isotherm parameters for total phenols adsorption in FTOP-1, FTOP-2, UF-1, UF-2 and NF-1 on MN200 resin at room temperature $\left(21 \pm 1^{\circ} \mathrm{C}\right)$.

Table 7. Adsorption and desorption phenols percentage for the first and latest cycle carried out in the useful life of MN200 study. 